\title{
Effect of Naringerin on Biochemical Parameters in the Streptozotocin-Induced Diabetic Rats
}

\author{
Ana Angélica Henrique Fernandes ${ }^{1 *}$, Ethel Lourenzi Barbosa Novelli ${ }^{1}$, Ary Fernandes \\ Junior $^{2}$ and Cristiano Machado Galhardi ${ }^{1}$ \\ ${ }^{I}$ Departamento de Química e Bioquímica; ${ }^{2}$ Departamento de Microbiologia e Imunologia; Instituto de Biociências; \\ Universidade Estadual Paulista; São Paulo - SP - Brasil
}

\begin{abstract}
Amongst the numerous co-adjuvant therapies which could influence the incidence and progression of diabetic complications, antioxidants and flavonoids are currently being tested in clinical trials. We investigated the effect of naringerin on biochemical parameters in streptozotocin-induced (STZ - $60 \mathrm{mg} / \mathrm{kg}$, i.p.) diabetic rats. Male rats were divided into four groups: G1: untreated controls; G2: normal rats receiving naringerin; G3: untreated diabetics; G4: diabetics rats receiving naringerin. The naringerin $(50 \mathrm{mg} / \mathrm{kg}$, i.p,) decreased the hyperglycaemia and hyperlipidaemia associated with STZ-diabetes. The concentrations of serum insulin in treated diabetic rats tended to be increased. Naringerin treatment prevents STZ-induced changes in the activities of ALT, AST and LDH in the liver and heart, indicating the protective effect of naringerin against the hepatic and cardiac toxicity caused by STZ. The glycogen level in cardiac and hepatic tissues elevated with naringerin in diabetic rats. The naringerin can improve the glucose and lipid metabolism and is beneficial in preventing diabetic complications.
\end{abstract}

Key words: Naringerin, hypoglycaemic activity, streptozotocin, diabetes mellitus, aminotransferases, hepatic and cardiac tissues

\section{INTRODUCTION}

Flavonoids are a group of naturally occurring polyphenolic compounds ubiquitously found in fruits and vegetables. The flavonoids are frequently components of the human diet, and intake may reach 800 mg/day (Yang et al., 2001; Amié et al., 2003).

The biological activities of the flavonoids have been extensively reviewed. Some were found to possess antiischemic, anti-inflammatory, antioxidant, antidiabetogenic properties and other effects have also been described. It is suggested that most of these biological effects are related to their antioxidant activity by various mechanisms, e.g. by scavenging or quenching free radicals, by chelating metal ions, or by inhibiting enzymatic systems responsible for the generation of free radicals (Mojzisova and Kuchta, 2001).

Considerable attention has been placed on understanding the pathophysiology of diabetes mellitus because of its importance in human health. Historically, the study of the pathogenesis of diabetes mellitus was in the traditional pattern of endocrinology: the major dysfunction of B-cells associated with the preovert phase of type I diabetes or with type II diabetes is a decreased secretory response to glucose (Defraigne, 2005). Hyperglycemia is characteristic of type I and type II diabetes mellitus, which is mainly caused by insulin deficiency and/or a failure of normal

\footnotetext{
* Author for correspondence: angelica@ibb.unesp.br
} 
insulin levels to stimulate glucose uptake in tissue. Although defects in glucose homeostasis have been recognized for decades, the molecular mechanisms involved in impaired whole body glucose uptake are still not understood. It is now clear, however, that the aggressive control of hyperglycemia can attenuate the development of chronic complications (Pinent et al., 2004).

Type I diabetes results from $\beta$ destruction that is generally considered to be a multifactorial autoimmune process.

After insulin became available, evidence emerged suggesting that human diabetes mellitus has a multifactotial aetiology. Insulin was the principle hypoglycaemic medication used in diabetes mellitus treatment (Souza and López, 2004). In order to discover other hypoglycaemic agents, many investigations have been performed in traditional medicine testing eventual hypoglycaemic naturals (Keenoy et al., 2005; Bonnefont et al, 2004).

Among animal models of diabetes mellitus, streptozotocin rat was considered especially as a precious tool to study both pathophysiological mechanisms of diabetes mellitus and hypoglycaemic activity of natural products (El Fiky et al., 1996).

Streptozotocin was recognised as a toxic agent for B-cells of the islets of Langerhans (Agarwal 1980), and has since then been widely used for the induction of diabetes mellitus with concomitant insulin deficiency (Bolzán and Bianchi, 2002).

Changes in concentrations of plasma lipids including cholesterol and lipoprotein are complication frequently observed in patients with diabets mellitus and certainly contributes to the development of coronary heart disease in these patients (Soyers et al., 2001; Galletto et al., 2004; Wold et al., 2005).

A high dietary content of fresh fruits and vegetables has been positively associated with a reduced incidence of coronary heart disease (CHD) by several epidemiological studies (Spignoli, 2000). The Zutphen Elderly Study found an inverse association between the consumption of flavonoids, mortality from CHD and incidence of myocardial infarction.

Flavonoids are certainly a biomarker of a "health" diet (high content of fibers, vegetables and simple carbohydrates; low content of lipids and complex carbohydrates; low caloric intake, etc) (Eastwood,
1999); however, behind these "unspecific" effects, recent biochemical and clinical investigations have focused on some "specific" effects of flavonoids on the cardiovascular system which may provide an explanation for the reduced CHD mortality in diabetic patients (Spignoli, 2000; Wilcox et al., 2000).

The abnormalities in lipid metabolism generally lead to elevation in the levels of serum lipids and lipoproteins that in turn play an important role in the occurrence of premature and severe atherosclerosis, which affects patients with diabetes (Ravi et al., 2005; Keenoy et al., 2005). Oxidative processes, such as the oxidative modification of LDL, appear to play an important role in the development of atherosclerosis in the arterial wall (Estebauer et al., 1992).

There is some evidence to suggest that flavonoids can be incorporated into lipoprotein within the liver or intestine and subsequently be transported within the lipoproteins particle. Naringenin has been shown also to associate with and penetrate lipid membranes. Therefore flavonoids, including narigenin, may be ideally located for protecting LDL from oxidation (Saija et al., 1995; Jung et al., 2004).

Moreover, diabetic patients exhibit abnormal antioxidant status proteins, auto-oxidation of glucose, excess glycosylated proteins (Lean et al., 1999) and oxidation of low density lipoprotein (LDL) (Mathiesen et al., 1996).

Diabetes mellitus is associated with increased lipid peroxidation, which may contribute to long-term tissue damage. Investigation of the pathophysiology of the secondary complications of diabetes is increasingly focusing on the role of flavonoids. In nonhuman primates, dietary genistein, the isoflavone analog of naringenin, significantly reduces plasma LDL and VLDL cholesterol levels (Wilcox, et al., 2000). Flavonoid consumption was inversely associated with mortality from CHD. Relative risks for CHD mortality and first myocardial infarction were approximately $50 \%$ lower in the highest tertile of flavonoid intake (Wilcox, et al., 2000; Sugiura et al., 2006).

In this study, we examined whether dietary naringerin useful in the prevention of diabetic complications caused by streptozotocin, through the in serum and tissue biochemical parameters. 


\section{MATERIAL AND METHODS}

\section{Experimental Animals}

Experiment was performed on adult male wistar rats at weights ranging from 250 to $300 \mathrm{~g}$. The animals were maintained at a room temperature of $22 \pm 2^{\circ} \mathrm{C}$ with $12 \mathrm{~h}$ light/dark cycle and $50 \pm 5 \%$ relatively humidity and were fed rat chow diet (Purina Co., St. Louis, MO.), and water ad libitum. The animals used in the present study were maintained in accordance with the principles and guidelines of the Canadian Council on Animal Care as outlined in "Guide for the Care and Use of Laboratory Animals".

\section{Streptozotocin-induced diabetes mellitus}

Experimental diabetes was induced by a single intraperitoneal injection of streptozotocin (Sigma, St. Louis, MO.) at a dose of $60 \mathrm{mg} \mathrm{kg} \mathrm{g}^{-1}$ body weight $(1 \mathrm{~mL}$ freshly prepared solution in $0.1 \mathrm{M}$ citrate buffer, $\mathrm{pH} 4.5$ ). Non- diabetic control rats were injected with the citrate buffer alone. Fortyeight hours after streptozotocin administration the blood glucose was monitored. Only streptozotocin-treated rats with blood glucose greater than $16.5 \mathrm{mmol} / \mathrm{L}$ were considered diabetic and included in the study.

\section{Test Naringerin}

Seven days after administration the injection of streptozotocin, the naringerin (Sigma, St. Louis, MO, USA) was dissolved in propylenglycol as a vehicle and injected intraperitoneally to rats once a week at a dosage of $50 \mathrm{mg} \mathrm{kg}^{-1}$ body weight, for 30 days.

\section{Experimental procedure}

A total of 40 rats were used. The animals were randomly divided into four groups of 10 animals in each. Group I (untreated controls): normal rats receiving water and fed ad libitum and served as a control group; Group II (treated controls): normal rats receiving water and fed ad libitum and naringerin; Group III (untreated diabetics): diabetic rats receiving water and fed ad libitum and served as diabetic control rats and Group IV (treated diabetics): diabetic rats receiving water and fed ad libitum and naringerin.

The food intake $(\mathrm{g})$ and water intake $(\mathrm{mL})$ of individual rats was measured daily. Body weight (g) of the rats was measured weekly. After 30 days, the animals were deprived of food overnight and sacrificied by decapitation.

\section{Biochemical analysis of serum and tissues}

Blood glucose concentration was determined by automatic glucose analyser (Boehringer Mannheim, Eli Lilly Ltd, São Paulo, Brazil).

Serum insulin concentration was determined by enzyme immune assay kit (EIA kit, Cayman Chemical, USA), using an ELISA reader (Biotech Instruments, INC, USA).

Total cholesterol levels were measured using a cholesterol ester/oxidase enzymatic procedure. High density lipoprotein (HDL) levels were measured directly using an enzymatic colorimetric method that incorporated polyethylene glycolmodified cholesterol ester oxidase. Low density lipoprotein (LDL) was calculated by the Friedewald formula. Serum glucose levels were determined by using GOD/POD enzymatic method.

Triacylglycerols concentration was assayed enzymatically with glycerol kinase after lipase hydrolysis Soloni (1971).

The enzymatic activities of alanine aminotransferase (ALT - E.C. 2.6.1.2), aspartato aminotransferase (AST - E.C. 2.6.1.1) and lactate dehydrogenase (LDH - E.C. 1.1.1.27) in serum, liver and heart were measured by the enzymatic method of Reitman and Frankel (1957), following the rate of oxidation of NADH during the reaction which is proportional to alanine aminotransferase, aspartate aminotransferase and lactate dehydrogenase activities.

Samples of $200 \mathrm{mg}$ of the liver and heart (left ventricle) were homogenized in $0.6 \mathrm{M}$ perchloric acid and the amount of free glucose determined using the glucose oxidase procedure (test kit CELM, Modern Laboratory Equipment Company, São Paulo, Brazil). Tissue glycogen was then hydrolysed to glucose directly in homogenates by treatment with amyloglucosidase (Sigma, St. Louis, MO, USA) and the glucose released was measured. The glycogen level was calculated as the difference between total and free glucose (Roehrig and Allred, 1974).

The hepatic triacylglycerol was extracted usind the procedure developed by Bligh and Dyer, (1959). Part of the sample (approximately 200mg) was homogenized in chloroform-methanol 2:1 (v/v); the chloroform layer containing all the lipids and the methanolic layer containing all the non-lipids (Soloni, 1971).

Samples of $200 \mathrm{mg}$ of the liver and heart (left ventricle) were homogenized in $5 \mathrm{~mL}$ chilled 0,01 $\mathrm{M}$ phosphate buffer (pH 7.4) with Potter-Elvehjem 
homogenizer. The homogenates were centrifuged at $12000 \mathrm{xg}$ for $20 \mathrm{~min}$ at $4^{\circ} \mathrm{C}$ (Pereira et al., 1998), and then the supernatant fractions were used for activities the of aspartate and alanine aminotransferase and dehydrogenase lactate.

\section{Statistical analysis}

Values reported are expressed as mean \pm SEM. Statistical significance of the difference between groups was determined by analysis of variance (ANOVA) followed by Tukey's test. The values were considered to be significantly different when the $P$ value was less than 0.05 (Zar, 1996).

\section{RESULTS}

The body weight gain for the non-diabetic rat group (I and II) was higher than those of the diabetic rat group (III and IV); while that untreated diabetic rat group (III) gained less $(p<0,05)$ wheight than treateds diabetic rat group (IV).
However, administration of the naringerin increased body weight gain in diabetic rats (Table1).

The food intakes was significantly increased in the untreated STZ- diabetic rat group (III) $(p<0,05)$ when compared with others groups (I, II and IV). Similarly, the water intakes was significantly greater $(\mathrm{p}<0,05)$ in the untrated STZ-diabetic rat group (III).

The influence of dietary naringerin on serum biochemical parameters in non-diabetic rat and diabetic rats are presented in Table 2 . Insulin levels in serum were significantly lower $(p<0,05)$ in the diabetic group than in controls. However, there were no significant differences between the untreated and treated diabetic rats for the serum insulin concentrations. The levels of glucose, total cholesterol, LDL-cholesterol and triacylglycerol in the serum of the diabetic rat group administered naringerin (IV) were lower $(\mathrm{p}<0,05)$ than in the untreated diabetic rat group (III). Whereas that HDL-cholesterol level was significantly higher.

Table 1 - Effect of naringerin on body weight gain, food and water intakes in non-diabetic and STZ diabetic rats after 4 weeks.

\begin{tabular}{|c|c|c|c|c|}
\hline \multirow{2}{*}{ Parameters } & \multicolumn{4}{|c|}{ Groups } \\
\hline & $\mathbf{I}$ & II & III & IV \\
\hline Body weight gain $g$ & $146.44 \pm 17.00 \mathrm{c}$ & $147.26 \pm 13.96 \mathrm{c}$ & $7.81 \pm 2.64 a$ & $97.04 \pm 10.54 b$ \\
\hline Food intakes $g \mathrm{rat}^{-1} \mathrm{day}^{-1}$ & $27.75 \pm 5.78 \mathrm{a}$ & $32.22 \pm 10.11 \mathrm{a}$ & $48.85 \pm 12.47 \mathrm{~b}$ & $30.40 \pm 8.11 \mathrm{a}$ \\
\hline Water intakes $m L \mathrm{rat}^{-1} d a y^{-1}$ & $48.27 \pm 8.01 \mathrm{a}$ & $51.57 \pm 10.15 \mathrm{ab}$ & $109.43 \pm 25.31 \mathrm{c}$ & $58.35 \pm 9.02 b$ \\
\hline
\end{tabular}

Table 2 - Effect of naringerin on serum in non-diabetic and STZ-diabetic rats after 4 weeks.

\begin{tabular}{lcccc}
\hline Biochemical & \multicolumn{4}{c}{ Groups } \\
\cline { 2 - 5 } Parameters & I & II & III & IV \\
\hline Insulin $n g / m l$ & $1.35 \pm 0.34 \mathrm{~b}$ & $1.30 \pm 0.22 \mathrm{~b}$ & $0.29 \pm 0.10 \mathrm{a}$ & $0.46 \pm 0.18 \mathrm{a}$ \\
Glucose $\mathrm{mmol} / \mathrm{L}$ & $10.59 \pm 2.15 \mathrm{a}$ & $10.84 \pm 1.59 \mathrm{a}$ & $34.34 \pm 4.03 \mathrm{~b}$ & $12.21 \pm .2 .37 \mathrm{a}$ \\
Total cholesterol mmol/L & $3.16 \pm 0.42 \mathrm{ab}$ & $3.07 \pm 0.47 \mathrm{a}$ & $4.16 \pm 1.14 \mathrm{~b}$ & $2.84 \pm 0.62 \mathrm{a}$ \\
LDL-Cholesterol mmol/L & $2.52 \pm 0.42 \mathrm{a}$ & $2.25 \pm 0.41 \mathrm{ac}$ & $3.18 \pm 1.25 \mathrm{ab}$ & $1.77 \pm 0.62 \mathrm{c}$ \\
HDL-cholesterol $\mathrm{mmol} / \mathrm{L}$ & $0.18 \pm 0.08 \mathrm{a}$ & $0.22 \pm 0.09 \mathrm{ab}$ & $0.18 \pm 0.03 \mathrm{a}$ & $0.29 \pm 0.13 \mathrm{~b}$ \\
Triacylglycerols $\mathrm{mmol} / \mathrm{L}$ & $0.94 \pm 0.24 \mathrm{a}$ & $1.27 \pm 0.35 \mathrm{a}$ & $3.77 \pm 0.49 \mathrm{~b}$ & $1.15 \pm 0.15 \mathrm{a}$ \\
\hline Values are expressed as means \pm SD $(n=10)$. In each row, values not sharing a common superscript roman letter are significantly different at p< \\
0. 05. Group I: untreated controls; group II: treated controls; group III: untreated diabetics; group IV: treated diabetics.
\end{tabular}

Activities of alanine aminotransferase (ALT), aspartate aminotransferase (AST) and lactate dehydrogenase $(\mathrm{LDH})$ were increased in the serum of untreated diabetic animals. However, the serum ALT, AST and LDH did not return to the basal level compared to untreated controls (I) (Table 3).
When narigerin was administered to diabetic rats, hepatic activities ALT and AST increased $(p<0,05)$. The data in Table 3 show that naringerin in diabetic rats caused an increase in cardiac tissue activities of AST and LDH. 
Table 3 - Effect of naringerin on the activity of ALT, AST and LDH in the liver, heart and serum in non-diabetic and STZ-diabetic rats after 4 weeks

\begin{tabular}{lcccc}
\hline Enzymatic activity & \multicolumn{4}{c}{ Groups } \\
\hline Serum IU/L & I & II & III & IV \\
\hline AST & $84.22 \pm 13.90 \mathrm{a}$ & $85.04 \pm 18.52 \mathrm{a}$ & $189.18 \pm 16.47 \mathrm{~b}$ & $87.38 \pm 12.52 \mathrm{a}$ \\
ALT & $50.26 \pm 4.61 \mathrm{a}$ & $55.49 \pm 5.59 \mathrm{a}$ & $120.18 \pm 13.54 \mathrm{~b}$ & $66.38 \pm 2.52 \mathrm{a}$ \\
LDH & $159.05 \pm 16.48 \mathrm{a}$ & $166.23 \pm 12.35 \mathrm{a}$ & $262.30 \pm 26.68 \mathrm{~b}$ & $170.08 \pm 11.24 \mathrm{a}$ \\
\hline Liver IU/mg protein & & & & \\
\hline AST & $141.76 \pm 16.87 \mathrm{~b}$ & $135.19 \pm 8.63 \mathrm{~b}$ & $77.72 \pm 7.49 \mathrm{a}$ & $122.72 \pm 15.09 \mathrm{~b}$ \\
ALT & $73.02 \pm 14.81 \mathrm{~b}$ & $70.98 \pm 4.38 \mathrm{~b}$ & $54.18 \pm 4.60 \mathrm{a}$ & $68.40 \pm 5.36 \mathrm{~b}$ \\
\hline Heart IU/mg protein & \multicolumn{5}{c}{} \\
\hline AST & $77.88 \pm 6.42 \mathrm{~b}$ & $80.92 \pm 8.92 \mathrm{~b}$ & $48.78 \pm 6.15 \mathrm{a}$ & $75.70 \pm 8.29 \mathrm{~b}$ \\
LDH & $151.64 \pm 12.07 \mathrm{~b}$ & $149.73 \pm 11.76 \mathrm{~b}$ & $125.76 \pm 10.50 \mathrm{a}$ & $143.95 \pm 9.07 \mathrm{~b}$ \\
\hline VDH
\end{tabular}

Values are expressed as means \pm SD $(n=10)$. In each row, values not sharing a common superscript roman letter are significantly different at $\mathrm{p}<$ 0. 05. Group I: untreated controls; group II: treated controls; group III: untreated diabetics; group IV: treated diabetics.

As shown in Table 4, dietary naringerin caused a significant improvement on these parameters of lipid metabolism (triacyglycerols) in the liver tissue of diabetic animals (group IV). In diabetic animals, naringerin reduced the rise in hepatic triacylglycerol level. In addition, hepatic glycogen increased significantly in treated diabetic rats (group IV) compared to untreated diabetic rats (group III). The liver weights (\% body weight) for the diabetic rat (group III) were higher than those of the non diabetic rats (group I).

As shown in Table 5, cardiac tissue glycogen concentration was significantly higher in treated diabetic rats than in untreated diabetic rats. Triacylglycerol levels, however, were unaffected by streptozotocin injection or naringerin administration.

Table 4 - Effect of naringerin on liver in non-diabetic and STZ - diabetic rats after 4 weeks.

\begin{tabular}{lcccc}
\hline Parameters & \multicolumn{4}{c}{ Groups } \\
\cline { 2 - 5 } Biochemical & I & II & III & IV \\
\hline Liver weight \% body weight & $4.38 \pm 1.47 \mathrm{a}$ & $4.72 \pm 1.56 \mathrm{a}$ & $8.93 \pm 1.80 \mathrm{~b}$ & $5.74 \pm 1.66 \mathrm{a}$ \\
Triacylglycerols mmol/g tissue & $0.10 \pm 0.01 \mathrm{a}$ & $0.12 \pm 0.02 \mathrm{a}$ & $0.24 \pm 0.03 \mathrm{~b}$ & $0.12 \pm 0.01 \mathrm{a}$ \\
Glycogen mmol/g tissue & $1.90 \pm 0.22 \mathrm{a}$ & $1.72 \pm 0.19 \mathrm{a}$ & $1.22 \pm 0.14 \mathrm{~b}$ & $1.84 \pm 0.19 \mathrm{a}$ \\
\hline Vay
\end{tabular}

Values are expressed as means $\pm \mathrm{SD}(n=10)$. In each row, values not sharing a common superscript roman letter are significantly different at $\mathrm{p}<$ 0. 05. Group I: untreated controls; group II: treated controls; group III: untreated diabetics; group IV: treated diabetics.

Table 5 - Effects of naringerin on heart in non-diabetic and STZ - diabetic rats after 4 weeks.

\begin{tabular}{lcccc}
\hline Parameters & \multicolumn{4}{c}{ Groups } \\
\cline { 2 - 5 } Biochemical & I & II & III & IV \\
\hline Triacylglycerols mmol/g tissue & $0.03 \pm 0.004 \mathrm{a}$ & $0.04 \pm 0.005 \mathrm{a}$ & $0.03 \pm 0.004 \mathrm{a}$ & $0.03 \pm 0.005 \mathrm{a}$ \\
\hline Glycogen $\mathrm{mmol} / \mathrm{g}$ tissue & $1.10 \pm 0.08 \mathrm{a}$ & $1.02 \pm 0.09 \mathrm{a}$ & $0.58 \pm 0.04 \mathrm{~b}$ & $1.00 \pm 0.09 \mathrm{a}$ \\
\hline $\begin{array}{l}\text { Values are expressed as means } \pm \text { SD }(n=10) \text {. In each row, values not sharing a common superscript roman letter are significantly different at } \mathrm{p}< \\
\text { 0. 05. Group I: untreated controls; group II: treated controls; group III: untreated diabetics; group IV: treated diabetics. }\end{array}$
\end{tabular}

\section{DISCUSSION}

The present study was designed to investigate actions of naringerin on serum and tissue biochemical parameters in STZ-induced diabetic rats and normal non-diabetic rats. Following injection with streptozotocin, these animals displayed the expected symptoms of insulindependent diabetes mellitus, i.e., hyperglycemia, polydipsia, depression of body mass gain, the increase in food and water intake and the decrease in insulin concentration, as previously observed for Mak et al, (1996) and Robert (2001).

The administration of naringerin $\left(50 \mathrm{mg} \mathrm{kg}^{-1}\right)$ to STZ-diabetic rats caused a statistically significant reduction in food and water intakes, and an increase in the body weight gain. This could be the result of improved glycemic control produced by naringerin. 
In our study, it is evident from the above results that the naringerin reduced $(p<0,05)$ serum glucose in STZ-diabetic rats.

The serum glucose lowering effect in the absence of a significant change in serum insulin concentration suggest that the naringerin treatment may involve an insulin-independent-mechanism. The naringerin might be producing its hypoglycaemic effect by an extra-pancreatic action, e.g., possibly by stimulating glucose utilization in extra-hepatic tissues or increases in the expression of insulin receptors in the liver plasma membranes (Jouad et al., 2000; Patel et al., 2001; Mezei et al., 2003; Pinent et al., 2004). Flavonoids are able to indirectly participate in the reduction of oxidative stress in diabetic patients by improving glycemic control and/or are able to exert antioxidant activity (Bonnefont, 2004).

The increase of glucose utilization by myricetin was further characterized using the enhancement of glycogen synthesis in hepatocytes of STZdiabetic rats (Liu et al., 2005).

This decrease in the glucose concentration is in part explained by an effect of naringerin on the metabolism and in part by the direct action of naringerin on cell membranes. The flavonoid exert their effect by either promoting the entry of glucose into cells, stimulation of glycolytic enzymes and glycogenic enzymes, depression of gluconeogenic enzymes or inhibiting the glucose6-phosphatase in the liver, subsequently reducing the release of glucose in the blood (Naik et al., 1991).

Alterations in plasma lipoprotein metabolism are common in diabetes, which tend to exaggerate any pre-existing tendencies towards elevated lipid levels (Merzouk et al., 2004). In addition, diabetes is associated with increased dyslipidaemia (Brown and Goldstein, 1999; Daniel et al., 2003). A number of reports have suggested that these compounds may also influence atherogenesis through an effect on lipid and lipoprotein metabolism (Wilcox et al., 2000).

The levels of triacylglycerols and total cholesterol in the serum of the diabetic rats had been reported to be greatly elevated (Mak et al., 1996; Wittenstein et al., 2002). The rise in serum triacylglycerols, cholesterol and LDL-cholesterol levels in present study indicate a derangement in the lipid metabolism and increased incidence of cardiac dysfunction in diabetic pacients. Elevation of serum lipids indicates either the defective removal or overproduction (or both) of one or more lipoproteins (Akula et al., 2003). The level of triacylglycerols, total cholesterol and LDLcholesterol in the serum of the diabetic rat groups administered naringerin (group IV) was lower $(\mathrm{p}<0,05)$ than in the diabetic rat group (III). Flavonoids decreased the triacyglycerols and total cholesterol in the blood of rats (Miyake et al., 1998). Naringerin is potent agents for the inhibition of HMG-CoA reductase and also benefical for lowering serum cholesterol levels (Bok et al., 1999).

Consequently, these results indicate that administration of naringerin facilitates lipid metabolism in the diabetic rats. It has been suggested that dietary flavonoids may be antiatherogenic agents.

The decrease of LDL levels may occur due to the reduction of VLDL and the increase of hepatic depuration of LDL precursors (Knekt et al., 2002). In nonhuman primate, dietary genistein, the isoflavone analog of naringenin, significantly reduces plasma LDL and VLDL cholesterol levels (Wilcox et al., 2000).

Results of HDL-cholesterol, shown in the Table 2, evidence that the best treatment was accomplished with naringerin (group IV). That is an advantage, since HDL-cholesterol is responsible for the transportation of cholesterol from peripheric tissues to the liver for metabolization. Naringerin thus has the potential to prevent the formation of atherosclerosis and coronary heart disease which are the secondary diabetic complications of severe diabetes mellitus (Nigdikar et al., 1998).

The present study was carried out to examine the protecting effect of the naringerin on the changes in the enzymatic activities in the serum, liver and heart injured by the exposure to streptozotocin in rats.

Elevated activities of serum aminotransferases are a common sign of liver and cardiovascular diseases and are observed more frequently among people with diabetes than in the general population (Arkkila et al., 2001).

Naringerin treatment prevented both the decrease in AST, ALT and LDH activities in the liver and heart and the increase in these enzymatic activities in serum that was caused by STZ administration. Antioxidants inhibited the increase in serum levels of AST and ALT in streptozotocin-treated mice (Imaeda et al., 2002).

Narigerin significantly lowered the pathway enzymes in diabetic rats and reversed the changes in enzyme activities of energy metabolisms that 
occurred due to diabetes. This beneficial effect may have resulted primarily from the hypoglycemia potencial of dietary flavonoids in diabetes (Bolkent et al., 2004).

Aminotransferases of hepatic tissue were low in diabetic rats, and dietary naringerin showed a pronounced reversing trend on this. Aminotransferases are involved in the interconversion of metabolic intermediates relative to energy metabolism and gluconeogenesis (Babu and Srinivasan, 1999). Therefore, naringerin has a protective effect against the hepatotoxicity produced by STZ-diabetes.

Liver weight, expressed as \% body weight, for the diabetic rat group (III) was higher than those of the non-diabetic rat group (I and II) because of the hypertrophy of the liver caused by the STZ induction (Table 4). These are typical symptoms of diabetic rats (Mak et al., 1996; Sugiura et al., 2006). The liver weight for the diabetic rat group administered naringerin (group IV) were significantly lower $(p<0,05)$ than for the diabetic rat group (III). The narigerin may play an important role for improvement of the hypertrophy of the liver in the diabetic rats.

Liver hypertrophy in diabetic rats is mainly due fat deposition (triacyglycerols - Table 4) stores in the liver.

Restoration of hepatic glycogen by naringerin could be due to inhibition of glucose-6phosphatase in the liver, thereby preventing conversion of glucose-6-phosphate to glucose (Wittenstein et al., 2002). The pathway of glycogen synthesis in liver is mainly via gluconeogenesis (indirect pathway) or a glucose phosphorylation step (direct pathway) (Mc Garry et al., 1987). Hence, glucose-6-phosphate formed can be converted to glycogen.

Hepatic glucokinase activity and glycogen concentration were both significantly elevated in the naringin-supplemented groups. Naringin also markedly lowered the activity of hepatic glucose6-phosphatase and phosphoenolpyruvate carboxykinase (Jung et al., 2004).

Naringin play important roles in preventing the progression of hyperglycemia, partly by increasing hepatic glycolysis and glycogen concentration and/or by lowering hepatic gluconeogenesis (Jung et al., 2004).

The glycogen content of the liver treated diabetic rats group (IV) may contribute to maintain a liver weight similar to that of the controls rats (I and II).

\section{RESUMO}

Dentre as numerosas terapias para minimizar as complicações diabéticas, os antioxidantes e flavonoides são testados na clínica médica. Foi analisado o efeito da naringerina sobre os parâmetros bioquímicos em ratos diabéticos induzidos por estreptozotocina $(\mathrm{STZ}-60 \mathrm{mg} / \mathrm{kg}$, i.p.). Ratos machos foram divididos em 4 grupos: G1: controle não tratado; G2: ratos normais que receberam naringerina; $\mathrm{G} 3$ : diabéticos não tratados; G4: ratos diabéticos que receberam naringerina. Naringerina $(50 \mathrm{mg} / \mathrm{kg}$, i.p. $)$, decresceu a hiperglicemia e a hiperlipidemia em ratos diabéticos. A concentração sérica de insulina em ratos tratados tendeu aumentar. A naringerina preveniu as alterações, provocadas pela estreptozotocina, na atividade hepática e cardíaca de ALT, AST e LDH, indicando o efeito protetor da naringerina sobre estes tecidos, contra toxicidade provocada pela STZ. O nível de glicogênio nos tecidos cardíaco e hepático elevou com a naringerina em ratos diabéticos. A naringerina melhorou o metabolismo da glicose e de lipídios e preveniu as complicações diabéticas.

\section{REFERENCES}

Agarwal, M. (1980), Streptozotocin: mechanism of action. FEBS Lett, 120, 1-3.

Akula, A., Kota, M.K. and Gopisetty, S.G. (2003), Biochemical, histological and echocardiographic changes during experimental cardiomyopathy in STZ-induced diabetic rats. Pharmacological Research, 48, 429-435.

Amié, D., Beslo, D. and Trinajsrie, N. (2003), Structure-radical scavenging activity relationships of flavonoids. Croatica Chemica Acta, 76, 55-61.

Arkkila, P.E., Koskinen, P.J., Kantola, I.M. and Viikari, J.S. (2001), Diabetic complications are associated with liver enzyme activities in people with type 1 diabetes. Diabetes Research and Clinical Practice, 52, 113-118.

Babu, P.S. and Srinivasan K. (1999), Renal lesions in streptozotocin-induced diabetic rats maintained on onion and capsaicin containing diets. $J$ Nutr Biochem..10, 477-483.

Bligh, E.G. and Dyer, W.J. (1959), A rapid method of total lipid extraction and purification. Canadian Journal of Biochemistry and Physiology, 37, 911917. 
Bok, S.H., Lee, S.H. and Park, Y.B. (1999), Plasma and hepatic cholesterol and hepatic activities of 3hydroxy-3-methyl-glutaryl-CoA reductase and acyl CoA: cholesterol transferase are lower in rats fed citrus peel extractor a mixture of citrus bioflavonoids. Journal Nutrition, 129, 1182-1185.

Bolkent, S., Yanardag, R., Karabulut, B.O. and Ozsoy, S.O. (2004), The morphological and biochemical effects of glibornuride on rat in experimental diabetes. Human and Experimental Toxicology, 23, 257-264.

Bolzán, A.D. and Bianchi, M.S. (2002), Genotoxicity of streptozotocin. Mutation Research, 512, 121-134.

Bonnefont, R.D. (2004), The role of antioxidant micronutrients in the prevention of diabetic complications. Treatments in Endocrinology, 3, 4152.

Brown, M.S. and Goldstein, J.L. (1999), Hyperlipoproteinaemias and other disorders of lipid metabolism. In- Isselbacher KJ (Eds.) Harrison's Principles of Internal Medicine, McGraw-Hill, New York, pp. 2068-2075.

Daniel, R.S., Devi, K.S., Augusti, K.T. and Sudhakaran, N.C.R. (2003), Mechanism of action of antiatherogenic and related effects of Ficus bengalensis Linn. Flavonoids in experimental animals. Indian J. Exp. Biol., 41, 296-303.

Defraigne, J.O. (2005), A central pathological mechanism explanism diabetic complications? Revue Medicale de Liege, 60, 472-478.

Eastwood, M.A. (1999), Interaction of dietary antioxidants in vivo: howfruit and vegetables prevent disease? QJM, 92, 527-530.

El Fiky, F.K., Abou-Karam, M.A. and Afify, E.A. (1996), Effect of Luffa aegyptiaca (seeds) and Carissa edulis (leaves) extracts on blood glucose level of normal and streptozotocin diabetic rats. $J$. Ethnopharmacol, 50, 43-47.

Esterbauer, H., Gebicki, J., Puhl, H. and Jurgens, G. (1992), The role of lipid peroxidation and antioxidants in oxidative modification of LDL. Free Rad. Bio.l Med., 13, 341-390.

Galletto, R., Siqueira, V.L.D., Ferreira, E.B., Braz, A.J., Bazotte, R.B. (2004), Absence of antidiabetic and hypolipidemic effect of Gymnema sylvestre in nondiabetic and alloxan-diabetic rats. Brazilian Archives of Biology and Technology, 47-4, 545-551.

Imaeda, A., Kaneko, T., Aoki, T., Kondo, Y., Nakamura, N., Nagase, H.and Yoshikawa, T. (2002), Antioxidative effects of fluvastatin and its metabolites against DNA damage in streptozotocintreated mice. Food and Chemical Toxicology, 40, 1415-1422.

Jouad, H., Eddouks, M., Dubois, M.A.L. and Lyoussi B. (2000), Hypoglycaemic effect os Spergularia purpúrea in normal and streptozotocin-induced diabetic rats. J. Ethnopharmacol., 71, 169-177.
Jung, U.J., Lee, M.K., Jeong, K.S. and Choi, M.S. (2004), The hypoglycemic effects of hesperidin and naringin are partly mediated by hepatic glucoseregulating enzymes in $\mathrm{C} 57 \mathrm{BL} / \mathrm{KsJ}-\mathrm{db} / \mathrm{db}$ mice. $J$. Nutr., 134, 2499-2503.

Keenoy, B.M.Y., Campenhout, V.A., Aerts, P., Vertommen, J., Abrams, P., Gaal L.F.V. and De Leeuw, I.H. (2005), Time course of oxidative stress status in the postprandial and postabsorptive states in type 1 diabetes mellitus: relationship to glucose and lipid changes. Journal of the American College of Nutrition, 24, 474-485.

Knekt, P., Kumpulainen, J. and Jarvinen, R. (2002), Flavonoid intake and risk of chronic diseases. Am. J. Clin. Nutr., 76, 560-568.

Lean, M.E.J., Noroozi, M., Kelly, I., Burns, J., Talwar, D. and Sattar, N. (1999), Dietary flavonol protect diabetic human lymphocytes against oxidative damage to DNA. Diabetes, 48, 176-181.

Liu, I.M., Liou, S.S., Lan, T.W., Hsu, F.L.and Cheng, J.T. (2005), Myricetin as the active principle of Abelmoschus moschatus to lower plasma glucose in streptozotocin-induced diabetic rats. Planta Med., 71, 617-621.

Mak, D.H.F., Li, P.C., Poon, M.K.T. and Ko, K.M. (1996), Alteration in tissue glutathione antioxidaant system in streptozotocin-induced diabetic rats. Mol. Cell Biochem., 62, 153-158.

Mathiesen, L., Malterud, K.E., Nenseter, M.S. and Sund, R.B. (1996), Inhibition of low density lipoprotein oxidation by myrigalone $\mathrm{B}$, a naturally occurring flavonoid. Pharmacology and Toxicology, 78, 143-146.

Mc Garry, J.D., Kuwajima, M., Newgard, C.B. and Foster, D.W. (1987), From dietary glucose to liver glycogen: the full circle round. Annu Rev. Nutr., 7, 51-73.

Merzouk, S., Hichami, A., Sari, A., Madani, S., Habane, S.N. and Khan, N.A. (2004), Impaired oxidant/antioxidant status and LDL-fatty acid composition are associated with increased susceptibility to peroxidation of LDL in diabetic patients. General Physiology and Biophysics, 23, 387-399.

Mezei, O., Banz, W.J., Steger, R.W., Peluso, M.R., Winters, T.A. and Shay, N. (2003), Soy isoflavones exert antidiabetic and hypolipidemic effects through the PPAR pathways in obese zucker rats and murine RAW 264.7 cells. Biochemical and Molecular Actions of Nutrients, 58, 1238-1243.

Miyake, Y., Yamamoto, K., Tsujihara, N. and Osawa, T. (1998), Protective effects of lemon flavonoids on oxidative stress in diabetic rats. Lipids, 33, 689-695.

Mojzisova, G. and Kuchta, M. (2001), Dietary flavonoids and risk of coronary heart disease. Physiol. Res., 50, 529-535. 
Naik, S.R., Dhuley, J.N. and Deshmukh, A. (1991), Probable mechanism of hypoglycaemic activity of bassic acid, a natural product isolated from Bumelia sartorum. J. Ethnopharmacol., 33, 37-44.

Nigdikar, S.V., Williams, N.R., Griffin, B.A. and Howard, A. (1998), Consumption of red wine polyphenols reduces the susceptibility of low-density lipoproteins to oxidation in vivo. Am. J. Clin. Nutr., 68, 258-265.

Patel, R.P., Boersma, B.J., Crawford, J.H., Hogg, N. and Kirk, M. (2001), Antioxidant mechanisms of isoflavones in lipid systems: paradoxical effects of peroxyl radical scavenging. Free Radical Biology and Medicine, 31,1570-1581.

Pereira, B., Costa-Rosa, L.F.B.P., Bechara, E.L.K. and Newsholme, P. (1998), Changes in the TBARs content and superoxide dismutase, catalase and glutathione peroxidase activities in the lymphoid organs and skeletal muscles of adrenomedullated rats. Brazilian J. Medical and Biological Research, 31, 827-833.

Pinent, M., Blay, M., Bladé, M.C., Salvadó, M.J. and Arola, L. (2004), Grape seed-derived procyanidins have an antihyperglycemic effect in streptozotociinduced diabetic rats and insulinomimetic activity in insulin-sensitive cell lines. Endocrinology, 145, 49854990.

Ravi, K., Rajasekaran, S. and Subramanian, S. (2005), Antihyperlipidemia effect of Eugenia Jambolana seed kernel on streptozotocin-induced diabetes in rats. Food Chem. Toxicol., 43, 1433-1439.

Reitman, S. and Frankel, S.A. (1957), Colorimetric method for the determination of serum glutamicoxaloacetic and glutamic pyruvic transaminases. Am. J. Clin. Pathol., 28, 56-63.

Robert, W.C. (2001), Ultrasound imaging: principles and applications in rodent research. Int. Lab. Anim. Res., 42, 233-247.

Roehrig, K. and Allred, J.B. (1974), Direct enzymatic produce for the determination of liver glycogen. Analytical Biochemistry, 58, 414-421.

Saija, A., Scalese, M., Marzullo, D., Bonina, F. and Castelli, F. (1995), Flavonoids as antioxidant agents:
Impotance of their interaction with biomembranes. Free Radic. Biol. Med., 19, 481-486.

Soloni, F.G. (1971), Simplified manual micromethod for determination of serum triglycerides. Clinical Chemistry, 17, 531-534.

Souza, A.M.F. and López, J.A. (2004), Insulin or insulin-like studies on unicellular organisms: a review. Brazilian Archives of Biology and Techonology, 47-6, 973-981.

Soyers, J.R., Epstein, M. and Frohlich, E.D. (2001), Diabetes, hypertension, and cardiovacular disease: an update. Hypertension, 37, 1053-1059.

Spignoli, G. (2000), Protective effects of dietary flavonoids on cardiovascular system and circulation. European Bulletin of Drug Research, 8, 1-8.

Sugiura, M., Ohshima, M., Ogawa, K. and Yano, M. (2006), Chronic administration of Satsuma mandarin fruit improves oxidative stress in streptozotocininduced diabetic rat liver. Biological and Pharmaceutical Bulletin, 29, 588-591.

Wilcox, L.J., Borradaile, M.N. and Huff, M.W. (2000), Antiatherogenic properties of naringerin, a citrus flavonoids. Cardiovascular Drug Reviews, 17, 160178.

Wittenstein, B., Klein, M., Finckh, B., Ullrich, K. and Kohlschutter, A. (2002), Plasma antioxidants in pediatric patients with glycogen storage disease, diabetes mellitus, and hypercholesterolemia. Free Radical Biology and Medicine, 33, 103-110.

Wold, L.E., Ceylan, I.A.F. and Ren, J. (2005), Oxidative stress and stress signaling: menace of diabetic cardiomyopathhy. Acta Pharmacologica Sinica, 26, 908-917.

Yang, B., Kotani, A., Arai, K. and Kusu, F. (2001),

Estimation of the antioxidant activities of flavonoids from their oxidation potentials. Analytical Sciences, 17, 599-604.

Zar JH. Biostatistical Analysis (1996), Prentice - Hall New Jersey, 718p. 